\title{
PENGARUH PENAMBAHAN BAHAN KOMPATIBILISASI PADA NILON DAUR ULANG TERHADAP KEKUATAN TRANSVERSAL BASIS GIGI TIRUAN NILON TERMOPLASTIK
}

\author{
Azizah Nurur Rahmah, Haslinda Z. Tamin \\ Departemen Prostodonsia, Fakultas Kedokteran Gigi, Universitas Sumatera Utara \\ Jl. Alumni No. 2 Kampus USU Medan 20155 \\ e-mail: azizahnurur@gmail.com
}

\begin{tabular}{l}
\hline KATA KUNCI \\
\hline Nilon termoplastik, \\
kompatibilisasi, serat \\
kaca, kekuatan \\
transversal
\end{tabular}

KEYWORDS

Thermoplastic nylon, compatibilizer, fiberglass, transversal strength

\begin{abstract}
ABSTRAK
Pendahuluan: Nilon termoplastik sebagai bahan basis gigi tiruan sangat diminati karena sifatnya yang fleksibel. Nilon dimanipulasi dengan teknik injection moulding. Teknik tersebut menghasilkan spru yang dapat didaur ulang akan tetapi menyebabkan penurunan sifat mekanis nilon termasuk kekuatan transversal. Upaya mengatasi penurunan sifat tersebut dilakukan modifikasi dengan penambahan bahan kompatibilisasi yaitu nilon termoplastik murni dan serat kaca, diharapkan dapat meningkatkan kekuatan transversal. Tujuan penelitian ini adalah untuk mengetahui pengaruh penambahan bahan kompatibilisasi pada nilon daur ulang terhadap kekuatan transversal basis gigi tiruan nilon termoplastik. Metode: Rancangan penelitian ini adalah eksperimental laboratoris, post-test only control group design. Sampel pada penelitian ini adalah nilon termoplastik berbentuk batang uji dengan ukuran 64 × $10 \times 3,3 \mathrm{~mm}$ sebanyak 28 sampel untuk 4 kelompok yaitu nilon murni (A), kombinasi $60 \%$ nilon murni dan $40 \%$ nilon daur ulang (B), kombinasi 50\% nilon murni dan 50\% nilon daur ulang (C), kombinasi 50\% nilon murni dan 50\% nilon daur ulang dengan penambahan serat kaca $1 \%$ (D), kemudian dilakukan uji threepoint bending. Data dianalisis dengan uji ANOVA satu arah serta uji LSD. Hasil: Berdasarkan uji ANOVA satu arah menunjukkan tidak ada perbedaan diantara empat kelompok. Uji LSD menunjukkan terdapat perbedaan yang signifikan antara kelompok $\mathrm{A}$ dan $\mathrm{C}(\mathrm{p}=$ 0,046, $\mathrm{p}<0,05)$, tetapi tidak terdapat perbedaan antara A dan D ( $\mathrm{p}=$ 0,7, p > 0,05). Simpulan: Penambahan nilon termoplastik murni dan serat kaca sebagai bahan kompatibilisasi pada nilon daur ulang dapat meningkatkan kekuatan transversal nilon daur ulang.
\end{abstract}

\section{ABSTRACT}

Introduction: Thermoplastic nylon as a denture base material is in great demand because of its flexible denture. Nylon is manipulated by the injection molding technique. The technique produces sprue which can be recycled but causes a decrease in mechanical properties including transverse strength. To resolve this problem the modifications were made with the addition of compatibilizer materials, they are pure thermoplastic nylon and glass fiber expected to increase transversal strength. The purpose of this study was to determine the effect of adding compatibilizer materials on recycled nylon toward transverse strength of thermoplastic nylon denture base. Method: The design of this study is an experimental laboratory, post-test only control group design. The samples in this study were thermoplastic 
nylon rod-shaped test with a size of $64 \times 10 \times 3.3 \mathrm{~mm}$ as many as 28 samples for 4 groups, namely pure nylon (A), a combination of $60 \%$ pure nylon and $40 \%$ recycled nylon (B), a combination of $50 \%$ pure nylon and $50 \%$ recycled nylon $(C)$, a combination of $50 \%$ pure nylon and $50 \%$ recycled nylon with the addition of fiberglass $1 \%(D)$, then three-point bending test was performed. Data were analyzed by oneway ANOVA test and LSD test. Results: Based on the one-way ANOVA test, there was no difference between the four groups. LSD test showed that there were significant differences between groups $A$ and $C(p=$ 0.046, $p<0.05)$, but there were no differences between $A$ and $D(p=$ 0.7, $p>0.05$ ). Conclusion: The addition of pure thermoplastic nylon and glass fibers as compatibilizer materials on recycled nylon can increase the transverse strength of recycled nylon.

\section{PENDAHULUAN}

Basis gigi tiruan merupakan bagian dari gigi tiruan yang bersandar pada jaringan lunak mulut dan merupakan tempat melekatnya anasir gigi tiruan. ${ }^{1}$ Pada dasarnya bahan basis gigi tiruan dibagi menjadi dua kelompok yaitu logam dan non logam. ${ }^{2}$ Bahan basis gigi tiruan non logam dibedakan menjadi dua yaitu termoset dan termoplastik. Termoset merupakan bahan yang akan mengalami perubahan kimia ketika dipanaskan. Termoplastik merupakan bahan yang dapat dilunakkan dengan pemanasan dan mengeras dengan pendinginan tanpa mengalami perubahan struktur kimia, contohnya: poliester termoplastik, asetal termoplastik, polikarbonat termoplastik, akrilik termoplastik, dan nilon termoplastik. ${ }^{3,4}$

Nilon termoplastik merupakan nama generik dari bahan polimer sintetik yang dikenal sebagai poliamida. Nilon termoplastik pertama kali dikenal sebagai basis gigi tiruan pada tahun 1950-an. Material tersebut merupakan hasil reaksi kondensasi antara heksa metildiamina dengan asam dikarboksilat. Nilon termoplastik biasanya digunakan sebagai alternatif basis gigi tiruan bagi pasien yang memiliki sensitivitas terhadap monomer metil metakrilat atau logam. ${ }^{4,5}$ Nilon termoplastik merupakan basis gigi tiruan yang dapat dibuat lebih tipis dengan ketebalan tertentu yang telah direkomendasikan sehingga sangat fleksibel, ringan, dan tidak mudah patah. ${ }^{5}$

Nilon termoplastik tidak mudah patah dikarenakan memiliki kekuatan transversal yang tinggi. Nilon termoplastik memiliki daya tahan tinggi terhadap kekuatan karena nilon termoplastik memiliki polimer crystalline. Crystalline merupakan struktural dari suatu material dimana atom-atomnya tersusun secara teratur berdasarkan panjang dan sudut ikatan tertentu. Polimer crystalline ini mengakibatkan nilon termoplastik memiliki ruang intermolekul yang padat sehingga terjadi peningkatan dalam sifat-sifat mekanisnya termasuk kekuatan transversal. ${ }^{3}$ Nilai kekuatan transversal bahan basis gigi tiruan termoplastik berdasarkan ISO 20795:2013 idealnya tidak kurang dari 65 MPa. ${ }^{6} \quad$ Uji kekuatan transversal sering 
dilakukan untuk mengukur sifat mekanis dari suatu basis gigi tiruan karena dianggap dapat mewakili tipe-tipe gaya selama proses pengunyahan. Kekuatan transversal merupakan kombinasi dari kekuatan tarik dan kekuatan geser. ${ }^{7}$

Nilon termoplastik tersedia dalam bentuk butiran sehingga perlu dipanaskan dalam temperatur yang cukup agar nilon termoplastik berubah menjadi cair dan dapat diinjeksikan ke dalam mold menggunakan injektor, teknik manipulasi ini disebut injection molding. Saat proses injeksi menggunakan injektor, cairan nilon termoplastik mengisi mold dengan melewati spru, sehingga nantinya material akan tersisa di spru dan memadat membentuk spru nilon. ${ }^{5,8}$ Spru nilon merupakan limbah yang tidak mampu terurai dalam jangka waktu tertentu. ${ }^{3,9}$ Penggunaan bahan polimer nilon termoplastik secara terus-menerus telah menyebabkan peningkatan jumlah nilon sisa yang dapat mencemari lingkungan, sehingga memotivasi para peneliti untuk lebih tertarik pada daur ulang nilon sisa dan penggunaan kembali limbah yang ada. ${ }^{10}$ Metode daur ulang limbah polimer plastik dapat dibagi menjadi empat yaitu, metode daur ulang primer, sekunder (mekanik), kimia, dan kuartener. $^{3}$ Berdasarkan sudut pandang industri, metode daur ulang mekanik yang paling sesuai dilakukan karena biayanya rendah dan mudah dilakukan. ${ }^{10}$

Metode daur ulang mekanik dapat memberikan efek negatif pada polimer. Soja dkk (2013) meneliti efek yang ditimbulkan dari daur ulang mekanik pada nilon sisa. Hasil pada Fourier Transformed Infrared Spectroscopy (FTIR) menunjukkan ratio methyl $\mathrm{CH} 3$ meningkat, sementara methylene $\mathrm{CH} 2$ menurun. Ini terjadi akibat degradasi polimer dimana ada pemotongan pada ikatan C-C sehingga menghasilkan ikatan yang lebih pendek dengan kelompok methylene yang lebih sedikit. Terjadi pemotongan C-C ini akan berdampak pada sifat mekanis dan fisis polimer. ${ }^{9}$

Upaya yang dapat dilakukan untuk memperbaiki penurunan sifat mekanis dari nilon daur ulang adalah dengan penambahan bahan kompatibilisasi yaitu bahan yang ditambahkan ke dalam polimer untuk meningkatkan interaksi tertentu. ${ }^{11}$ Bahan kompatibilisasi yang digunakan pada penelitian ini antara lain nilon termoplastik murni dan serat kaca. Beberapa penelitian sebelumnya menunjukkan penambahan nilon termoplastik murni kedalam nilon daur ulang dapat menciptakan struktur polimer yang lebih baik karena ikatan hidrogen nilon termoplastik murni akan mengisi daerah amorphous nilon daur ulang. ${ }^{9}$ Wijaya WP (2018) menunjukkan penambahan $60 \%$ nilon termoplastik murni ke dalam $40 \%$ nilon daur ulang menghasilkan nilai kekuatan fleksural yang sama baiknya dengan kelompok nilon termoplastik murni. ${ }^{12}$

Pada daur ulang mekanik penggabungan polimer murni, limbah dari polimer yang sama ditambah dengan bahan kompatibilisasi 
yang sesuai dapat menghasilkan sifat mekanis yang lebih baik dibandingkan dengan limbah polimer tersebut. ${ }^{10}$ Serat kaca merupakan bahan pengisi yang paling banyak digunakan dalam komposit berbasis termoplastik, karena bahan tersebut memiliki keseimbangan yang baik antara sifat yang dihasilkan dan biaya yang rendah. ${ }^{13}$ Penambahan serat kaca pada nilon termoplastik dapat memperbaiki sifat dari bahan dengan cara mengisi ruang yang kosong sehingga ikatan menjadi lebih baik dan berat molekul bertambah, dimana dalam hal ini serat kaca memiliki fungsi sebagai bahan kompatibilisasi dan sifat mekanis pun dapat diperbaiki. ${ }^{4,9}$

Serat kaca memiliki beberapa kelebihan yaitu dapat beradhesi dengan matriks poliamida, biokompatibel, tidak ada substansi karsinogenik, memiliki kualitas estetis yang baik serta dapat mengurangi penyerapan air sehingga mencegah penurunan kekuatan mekanis. $^{14}$ Ariyani (2013) menemukan bahwa penambahan serat kaca dapat menurunkan nilai penyerapan air pada nilon termoplastik. Serat kaca dapat mencegah air masuk ke dalam ikatan antar matriks sehingga ikatan kimia matriks polimer menjadi lebih baik dan kekuatan polimer meningkat. ${ }^{15}$ Unalan $\mathrm{F}$ dkk (2010) menyatakan bahwa serat kaca jenis E-glass bentuk potongan kecil dengan ukuran dan konsentrasi berbeda yang ditambahkan pada basis gigi tiruan lebih efektif meningkatkan kekuatan transversal daripada bentuk lain, karena serat kaca bentuk potongan kecil dapat tersebar lebih merata pada seluruh matriks polimer sehingga sifat yang dihasilkan lebih baik. ${ }^{14}$

Maka dari itu, penelitian ini bertujuan untuk mengetahui apakah pengaruh penambahan bahan kompatibilisasi berupa nilon termoplastik murni dan serat kaca pada nilon daur ulang terhadap kekuatan transversal basis gigi tiruan nilon termoplastik.

\section{METODE}

Rancangan penelitian yang digunakan adalah ekperimental laboratoris. Penelitian ini dilakukan di Unit Jasa Industri Fakultas Kedokteran Gigi Universitas Sumatera Utara dan Laboratorium Impact and Fracture Research Centre, Fakultas Teknik Mesin Universitas Sumatera Utara. Sampel pada penelitian ini adalah poliamida 6 (Bioplast, Japan) berbentuk batang dengan ukuran $64 \mathrm{~mm} \times 10 \mathrm{~mm} \times 3,3 \mathrm{~mm}$ (International Standards Organization No 1567) dibagi menjadi empat kelompok dan tiap kelompok berjumlah 7 sampel. Kelompok A adalah nilon termoplastik murni, kelompok B adalah kombinasi $60 \%$ nilon termoplastik murni dengan $40 \%$ nilon daur ulang, kelompok $\mathrm{C}$ adalah kombinasi $50 \%$ nilon termoplastik murni dengan $50 \%$ nilon daur ulang, dan kelompok D adalah kombinasi 50\% nilon termoplastik murni dengan $50 \%$ nilon daur ulang dengan penambahan serat kaca $1 \%$.

Nilon sisa didaur ulang dengan metode mekanik modifikasi yang meliputi beberapa 
tahap yaitu pemotongan, pemisahan dengan kontaminan menggunakan lekron dan larutan HCL $5 \mathrm{M}$, pencucian dengan air, dan pengeringan menggunakan desikator selama 24 jam dengan suhu $37^{\circ} \mathrm{C}$. Pada pemanipulasian serat kaca, serat kaca ditimbang terlebih dahulu sebanyak $1 \%$ dari berat nilon lalu di rendam dalam cairan silane coupling agent setelah itu dikeringkan pada suhu kamar selama 40 menit kemudian dimasukkan ke dalam oven pemanas selama 1 jam pada suhu $115^{\circ} \mathrm{C}$. Nilon dimanipulasi dengan teknik injection molding yaitu dengan cara dilelehkan dan diinjeksikan ke dalam kuvet di bawah tekanan. Kuvet disiapkan untuk proses injeksi kemudian furnace dinyalakan hingga panas suhu $250^{\circ} \mathrm{C}$. Setelah itu cartridge dimasukkan ke dalam furnace selama 15-30 menit hingga butiran termoplastik mencair. Bahan dalam cartridge diinjeksikan ke dalam mold selagi panas kemudian dibiarkan di bawah tekanan selama 3 menit dan biarkan selama 30 menit hingga mengeras dan kemudian dipoles.

Setelah sampel dipoles, sampel diberi nomor pada kedua ujungnya kemudian dilakukan pengujian. Pengujian kekuatan transversal dilakukan dengan menggunakan alat Universal Testing Machine (Tensilon RTF, japan) dengan cara memberikan tekanan pada sampel dengan kecepatan uji sebesar $1 / 10 \mathrm{~mm} /$ detik. Jarak antara kedua penyangga adalah $50 \mathrm{~mm}$. Lakukan penekanan pada bagian tengah sampel dengan memberikan beban yang meningkat secara bertahap sampai terjadi defleksi atau frakturnya sampel. Catat hasil uji lalu dilakukan perhitungan kekuatan transversal.

Rumus kekuatan transversal adalah sebagai berikut:

$$
\sigma=\frac{3 F I}{2 b d^{2}}
$$

\section{Keterangan:}

$\sigma=$ Kekuatan transversal (MPa)

$\mathrm{F}=$ Beban maksimum diterapkan $(\mathrm{N})$

$\mathrm{I}=$ Jarak antara kedua pendukung $(\mathrm{mm})$

$\mathrm{b}=$ Lebar batang uji (mm)

$\mathrm{d}=$ Ketebalan spesimen $(\mathrm{mm})$

\section{HASIL}

Hasil penelitian menunjukkan bahwa nilai rerata kekuatan transversal kelompok A adalah 79,903 MPa dengan standar deviasi sebesar 12,177. Nilai rerata kekuatan transversal kelompok B adalah 71,710 MPa dengan standar deviasi sebesar 10,748. Nilai rerata kekuatan transversal kelompok $\mathrm{C}$ adalah 68,645 MPa dengan standar deviasi sebesar 5,905. Nilai rerata kekuatan transversal kelompok D adalah 81,992 $\mathrm{MPa}$ dengan standar deviasi sebesar 10,180 (Tabel $1)$. 
Tabel 1. Nilai kekuatan transversal nilon termoplastik murni, kombinasi $60 \%$ nilon termoplastik murni dengan $40 \%$ nilon daur ulang, kombinasi $50 \%$ nilon termoplastik murni dengan $50 \%$ nilon daur ulang, dan kombinasi $50 \%$ nilon termoplastik murni dengan $50 \%$ nilon daur ulang dengan penambahan serat kaca $1 \%$

\begin{tabular}{ccccc}
\hline \multirow{4}{*}{$\begin{array}{c}\text { No } \\
\text { sampel }\end{array}$} & $\begin{array}{c}\text { Kekuatan Transversal (MPa) } \\
\text { Kelompok A } \\
\text { (100\% nilon } \\
\text { murni) }\end{array}$ & $\begin{array}{c}\text { Kelompok B } \\
\text { (kombinasi 60\% } \\
\text { nilon murni } \\
\text { dengan 40\% nilon } \\
\text { daur ulang) }\end{array}$ & $\begin{array}{c}\text { Kelompok C } \\
\text { (kombilon murni 50\% } \\
\mathbf{5 0 \%} \text { nilon daur } \\
\text { ulang) }\end{array}$ & $\begin{array}{c}\text { Kelompok D } \\
\text { (kombinasi 50\% nilon } \\
\text { murni dengan 50\% nilon } \\
\text { daur ulang dengan } \\
\text { penambahan serat kaca } \\
\mathbf{1 \% )}\end{array}$ \\
\hline 1 & $98,822^{* *}$ & 70,317 & 65,011 & 73,223 \\
2 & 86,481 & 78,788 & 72,899 & 84,070 \\
3 & 69,236 & 69,628 & 70,489 & 95,213 \\
4 & 70,937 & $85,193 * *$ & $62,579 *$ & 78,244 \\
5 & 75,682 & $57,536 *$ & $78,802 * *$ & $69,635 *$ \\
6 & 90,813 & 81,433 & 62,808 & 78,030 \\
7 & $67,353^{*}$ & 59,079 & 67,926 & $95,530^{* *}$ \\
\hline$x \pm S D$ & $79,903 \pm 12,177$ & $71,710 \pm 10,748$ & $68,645 \pm 5,905$ & $81,992 \pm 10,180$ \\
\hline
\end{tabular}

Keterangan: * nilai terkecil

*** nilai terbesar

Berdasarkan hasil uji ANOVA satu arah diperoleh tidak ada perbedaan nilai kekuatan transversal pada keempat kelompok tersebut dengan nilai $\mathrm{p}=0,059(\mathrm{p}>0,05)($ Tabel 2$)$.

Tabel 2. Hasil uji ANOVA satu arah

\begin{tabular}{cccc}
\multirow{3}{*}{ Kelompok } & \multicolumn{3}{c}{ Kekuatan Transversal (MPa) } \\
\cline { 2 - 4 } & $\mathrm{N}$ & $\bar{x} \pm \mathrm{SD}$ & $\mathrm{P}$ \\
\hline $\mathrm{A}$ & 7 & $79,903 \pm 12,177$ & \\
$\mathrm{~B}$ & 7 & $71,710 \pm 10,748$ & 0,059 \\
$\mathrm{C}$ & 7 & $68,645 \pm 5,905$ & \\
$\mathrm{D}$ & 7 & $81,992 \pm 10,180$ & \\
\hline
\end{tabular}

Berdasarkan hasil uji LSD terlihat perbedaan yang signifikan antara kelompok A dengan kelompok $\mathrm{C}$ dengan nilai $\mathrm{p}=0,046(\mathrm{p}<$ $0,05)$ tetapi tidak terdapat perbedaan antara kelompok perlakuan yaitu kelompok A dengan kelompok $\mathrm{D}$ dengan nilai $\mathrm{p}=0,7(\mathrm{p}>$ 0,05) (Tabel 3).
Tabel 3. Hasil uji LSD

\begin{tabular}{ccc}
\hline \multicolumn{2}{c}{ Kelompok } & $\mathrm{P}$ \\
\hline $\mathrm{A}$ & $\mathrm{C}$ & $0,046^{*}$ \\
\hline $\mathrm{A}$ & $\mathrm{D}$ & 0,700 \\
\hline
\end{tabular}

${ }^{*}$ Signifikan

\section{PEMBAHASAN}

Hasil penelitian menunjukkan bahwa terdapat nilai kekuatan transversal yang bervariasi pada setiap sampel dalam satu kelompok. Hal tersebut kemungkinan disebabkan oleh beberapa faktor yang mempengaruhi antara lain adanya mikroporositas yang terbentuk karena masuknya udara pada saat proses injeksi, hal ini dikarenakan bahan tidak sepenuhnya padat karena adanya udara yang terperangkap sehingga menyebabkan penurunan pada sifat mekanisnya. ${ }^{16}$ Selain itu, adanya kekasaran 
permukaan dikarenakan distribusi penekanan yang berbeda-beda pada saat proses pemolesan menggunakan pemegang sampel sehingga menimbulkan kekasaran permukaan pada sampel, dan derajat kristalin dimana ukuran kristal yang terbentuk akan semakin besar dan tidak padat karena pendinginan yang cepat, akibatnya terjadi penurunan pada kekuatan transversalnya. ${ }^{17}$ Nilai kekuatan transversal ideal suatu basis gigi tiruan bahan termoplastik berdasarkan ISO 20795-1: 2013 minimal yakni $65 \mathrm{MPa}^{6}$ Nilai rerata kekuatan transversal pada keempat kelompok penelitian ini masih di atas standard ISO dan berdasarkan hasil statistik terlihat tidak ada perbedaan antara keempat kelompok tersebut. Hal ini dikarenakan adanya penambahan nilon murni sehingga masih terjadi reaksi chain extension atau pemanjangan rantai. Nilon murni yang bertindak sebagai chain extenders akan meningkatkan berat molekul dengan melipatgandakan ikatan kimia yang mengalami degradasi ketika proses daur ulang berlangsung sehingga berat molekul nilon meningkat dan menghasilkan struktur nilon yang lebih baik. ${ }^{18}$

Nilai rerata kekuatan transversal terkecil pada penelitian ini adalah kelompok $\mathrm{C}$ yaitu kombinasi $50 \%$ nilon termoplastik murni dengan 50\% nilon daur ulang, hal ini dikarenakan persentase nilon daur ulang yang ditambahkan sama dengan persentase nilon murninya, dimana awalnya hal ini bertujuan untuk menggunakan lebih banyak lagi limbah daripada penelitian sebelumya. Meyabadi dkk (2010) mengungkapkan bahwa terjadinya penurunan sifat mekanis pada nilon daur ulang yang tidak dikombinasikan dengan nilon murni dan persentase nilon daur ulang harus di bawah persentase nilon murni untuk mendapatkan sifat mekanis yang optimal. ${ }^{19}$ Hal ini dibuktikan pada hasil penelitian ini dimana nilai kombinasi $60 \%$ nilon murni : $40 \%$ nilon daur ulang (kelompok B) lebih baik daripada kombinasi 50\% nilon murni : 50\% nilon daur ulang (kelompok C). Hal ini sejalan dengan penelitian Wijaya WP (2018) penambahan $60 \%$ nilon termoplastik murni pada $40 \%$ nilon daur ulang menghasilkan nilai kekuatan fleksural yang sama baiknya dengan kelompok nilon termoplastik murni. ${ }^{12}$ Perbedaan persentase nilon daur ulang berpengaruh terhadap kekuatan transversal karena semakin besar persentase nilon daur ulang yang ditambahkan ke dalam nilon murni, susunan polimer menjadi lebih renggang sehingga sifat mekanis akan semakin menurun. Soja dkk (2013) meneliti efek yang ditimbulkan dari daur ulang mekanik pada nilon sisa. Hasil pada Fourier Transformed Infrared Spectroscopy (FTIR) menunjukkan ratio methyl $\mathrm{CH} 3$ meningkat, sementara methylene $\mathrm{CH} 2$ menurun. Ini terjadi akibat degradasi polimer dimana ada pemotongan pada ikatan $\mathrm{C}-\mathrm{C}$ sehingga menghasilkan ikatan yang lebih pendek dengan kelompok methylene yang lebih sedikit. Terjadi pemotongan $\mathrm{C}-\mathrm{C}$ ini akan 
berdampak pada penurunan sifat mekanis dari nilon termoplastik. ${ }^{9}$

Nilai rerata kekuatan transversal pada kelompok kombinasi 50\% nilon murni : 50\% nilon daur ulang yang ditambahkan serat kaca $1 \%$ (kelompok D) lebih baik dibandingkan dengan kelompok lainnya. Hal ini menunjukkan kekuatan transversal tertinggi yaitu pada kelompok yang ditambahkan serat kaca konsentrasi $1 \%$ dengan rerata 81,992 MPa. Hal ini sejalan dengan pemelitian Vellasamy Y (2015) menunjukkan bahwa kekuatan transversal pada bahan basis gigi tiruan nilon termoplastik dengan penambahan serat kaca $1 \%$ lebih kuat dibandingkan dengan nilon termoplastik tanpa penambahan serat kaca 1\%. ${ }^{20}$ Ariyani (2013) menemukan bahwa penambahan serat kaca dapat menurunkan nilai penyerapan air pada nilon termoplastik. Serat kaca dapat mencegah air masuk ke dalam ikatan antar matriks dan mencegah terjadinya ekspansi matriks yang dapat melunakkan matriks dan membuat kekuatan polimer menjadi meningkat. Serat kaca juga dapat membuat ikatan antar matriks polimer menjadi lebih baik karena ruang kosong pada polimer terisi sehingga struktur polimer menjadi padat dan kekuatan polimer meningkat. ${ }^{15}$

\section{SIMPULAN}

Hasil penelitian ini menunjukkan ada pengaruh penambahan bahan kompatibilisasi serat kaca $1 \%$ dan $50 \%$ nilon termoplastik murni pada $50 \%$ nilon daur ulang terhadap kekuatan transversal basis gigi tiruan nilon termoplastik. Pada penelitian ini terlihat bahwa kombinasi $50 \%$ nilon termoplastik murni dan 50\% nilon daur ulang dengan penambahan serat kaca $1 \%$ akan menghasilkan nilai kekuatan transversal yang sama baiknya dengan kelompok murni. Namun, tetap harus memperhatikan sifatsifat mekanis yang lain serta sifat fisis, biologis, kimiawi, reologis, dan syarat-syarat lain yang diperlukan supaya dapat digunakan sebagai basis gigi tiruan.

\section{DAFTAR PUSTAKA}

1. Carr AB., Brownman DT, McCracken's Removable partial prosthodontics, $11^{\text {th }}$ ed, Elsevier, Canada, 2011.

2. Mapallil JJ., Basic dental materials, 3th ed, Jaypee Brothers Medical Publishers (P), New Delhi, 2010.

3. Grigore ME., Method of recycling, properties and application of recycled thermoplastic polymers, Journal Recycling, Volume 2, No.24: 1-11, 2017. DOI:10.3390/recycling2040024

4. Kohli S, Bhatia S., Polyamides in dentistry, International Journal of Scientifics Study. Volume 1, No. 1: 2025, 2013.

5. Seosetijo FXA. Pertimbangan laboratoris dan klinis nilon termoplastis sebagai basis gigi tiruan sebagian lepasan, Proceedings Book FORKINAS VI, 57-65: 2016

6. International Standart. The International Organization for Standardization. ISO 20795-1:2013.

7. Hafid IR. Sudibyo. Harniati ED., Kekuatan transversa termoplastik nilon pasca perendaman teh, kopi dan minuman isotonik, Prosiding Seminar Nasional Mahasiswa Unimus, Volume 1 : 12-19, 2018. 
8. Singh K, Gupta N., Injection molding technique for fabrication of flexible prosthesis from flexible thermoplastic denture base materials, World Journal of Dentistry, Volume 3, No.4: 303-307, 2012. DOI: $10.5005 /$ jp-journals-100151178

9. Soja J, Miskolczi N., Degradation of reinforced and unreinforced waste polyamides during mechanical recycling, Hungarian Journal of Industry and chemistry, Volume 4, No.2: 131-136, 2013. DOI:10.1515/513

10. Hamad K, Kaseem M, Deri F., Recycling of waste from polymer materials: an overview of the recent works, Journal Elsevier, Volume 98, No.12 : 2801-2812, 2013. DOI: org/10.1016/j.polymdegradstab.2013.09. 025

11. Setiorini IA., Sifat kuat tarik dan morfologi termoplastik elastomer dari komposit polypropylene dan natural rubbe, Jurnal Teknik Patra Akademika, Volume 8, No 1: 43-52, 2017

12. Wahyuni S, Wijaya WP., Pengaruh penambahan bahan kompatibilisasi pada nilon daur ulang terhadap kekuatan fleksural basis gigi tiruan nilon termoplastik. B-Dent: Jurnal Kedokteran Gigi Universitas Baiturrahmah, Volume 6, No.1: 43-49, 2018

13. Nurhajati DW, Sholeh M, Indrajati IN, Setyorini I., Pengaruh bahan pengisi serat kaca terhadap sifat fisik dan kristalinitas polipaduan pc/abs, Majalah Kulit Karet Plastik, Volume 33, No.1: 43-48, $2017 . \quad$ DOI: org/10.20543/mkkp.v33i1.2770

14. Unalan F, Dikbas I, Gurbuz O., Transverse strength of polymethylmethacrylate reinforced with different forms and concentrations of e- glass fibres. OHDMBSC, Volume 9, No.3 : 144-147, 2010.

15. Ariyani, Ismet DN, Harry A., Effect of thermocycling and e-glass fiber addition on water sorption and color stability of thermoplastic nylon denture base material, IOSR Journal of Dental and medical science, Volume 15: 41-48, 2016. DOI: 10.9790/0853-1508024148

16. Pero AC dkk, Reliability of a method for evaluating porosity in denture base resins, The gerodontology society and john wiley \& sons a/s gerodontology, Volume 28 : 127-133, 2011. DOI: 10.1111/j.1741-2358.2009.00347.x.

17. Dewan SK, Arora A, Sehgal MM., A comparative evaluation of flexural and impact strength of flexible and other denture base materials - an in vitro study. Indian Journal of Dental Sciences, Volume 7, No.1: 1-5, 2015.

18. Achilias DS et al., Recent advances in the chemical recycling of polymers (pp, ps, ldpe, hdpe, pvc, pc, nylon, pmma), Laboratory of Organic Chemical Technology, Department of Chemistry, Aristotle University of Thessaloniki, Greece, 2012.

19. Meyabadi TF, Mohaddes MMR, Mousav Shoustari SA., Melt spinning of reused nylon 6: structure and physical properties of as-spun drawn, and textured filaments, The Journal of the textile institute, Volume 101, No.6: 572537, 2010. DOI: $10.1080 / 00405000802561085$

20. Vellasamy Y., Pengaruh penambahan serat kaca terhadap penyerapan air dan kekuatan transversal serta modulus elastisitas bahan basis gigitiruan nilon termoplastik, Skripsi Kedokteran Gigi Program Sarjana Kedokteran Gigi, Universitas Sumatera Utara, Medan, 2015, Tidak Dipublikasikan. 